\title{
Sustainable municipal solid waste management in a capital city territory and the role of waste to energy: a study of Delhi
}

\author{
U. Dhamija \\ Delhi University, India
}

\begin{abstract}
In Delhi, in recent years, central, state and local level authorities have moved firmly towards the goal of scientific and sustainable management of solid waste generated from homes, offices and commercial establishments. A major initiative has been the decision to construct three waste-to-energy (WTE) projects. The government has pushed forward, despite the protests of environmental researchers and citizen groups who say these involve flawed, outdated and costly technologies which will add to pollution and erode livelihoods of the some of the poorest people in the city, without impacting much on its sanitation. Given the low calorific heterogeneous nature of the waste, they maintain, there is no alternative to waste reduction, composting, recycling and landfilling of residues. This paper will suggest that if the solid waste management hierarchy which expresses the spirit of the consensus that was arrived at in Rio de Janeiro in 1992 is the criterion, then, after two decades of economic reforms, WTE with its basis in advanced technology is an appropriate waste management strategy choice for Delhi. With the commissioning of the Okhla plant in January 2012, controversies relating to WTE regularly make the news. It is important that authorities address these concerns through appropriate measures such as transparent emission monitoring mechanisms and legal protection and benefits for waste workers in the informal sector. Dearth of land to accommodate mounting levels of mixed waste is creating an oppressive situation for urban planners in the developing world. Delhi's endeavour to resolve this problem by installing WTE facilities with the avowed object of enhancing public health, environment quality and economic efficiency and, as of now, staying with this decision, can be instructive for them.
\end{abstract}

Keywords: waste to energy, sustainable solid waste management, composting, recycling, waste workers, landfill, methane, biomethanation. 


\section{Introduction}

Increases in the rates of urbanization and population growth, intensification of economic activity and of consumption are distinguishing features of cities in low and middle income countries. Safe disposal of rising levels of a variety of solid waste - municipal, industrial, medical and electronic, which are a consequence of these developments pose a formidable challenge. The first type of waste, which is largely non-hazardous, differs from the rest due to its complex chemical composition and the huge quantity in which it gets generated every day. In recent years, in Delhi, public authorities have sought to come to grips with it, with capital intensive high technology measures. The results are mixed, but not discouraging.

\section{Territory of Delhi: a municipal solid waste related profile}

\subsection{Socio-economic underpinnings}

The national capital territory of Delhi, in which India's capital city New Delhi is located, is India's second most populous city after Mumbai and covers 1,483 square meters. In 2011, its population was 16.75 million. Though the decadal growth of population has declined since the 1980 s, the increase of $20.96 \%$ for 2001-2011 was still higher than the corresponding increase of $17.64 \%$ for the rest of India. The overall population density of Delhi moved up from 9,340 persons per sq. $\mathrm{km}$ in 2001 to 11,297 persons per sq. $\mathrm{km}$ in 2011 - the highest for a territory in India. The urban areas registered an increase while the rural declined further [1]. These demographic features are an indicator of the fact that since the economic reforms began in 1991-1992; Delhi continues to be a big draw for migrants from all parts of India due to the wide range of employment opportunities it offers in governance, construction, manufacture, trade, entertainment and services such as hospitality, transport, health and education. Relatively higher levels of income, despite sharp inequalities have facilitated the widespread adoption of a consumerist life style and the end result is that Delhi, at 8000 tons a day produces more solid waste than any other city in the country [2].

\subsubsection{Administrative aspects}

Although technically a federally administered union territory, Delhi is like any other state in India since it has its own legislature, high court and its own elected government headed by a Chief Minister. The city is divided into 12 zones. Three municipal bodies - the Municipal Corporation of Delhi (MCD), the New Delhi Municipal Council (NDMC) and the Delhi Cantonment Board (DCB), are responsible for solid waste management in Delhi. MCD alone manages it in almost $95 \%$ of the total area of the city. The MCD area includes urban areas, rural and urban villages, slum clusters, unauthorized and regularized unauthorized colonies. Under the Municipal Corporation Act of 1957, MCD is only required to provide receptacles in which people can deposit waste and which it then collects and transports for final disposal at the landfill or in any 
other manner. Fourteen landfills have already been used up and three are currently in use. The local governments are supported by a number of other agencies. These include the Department of Environment of Delhi government and the autonomous Delhi Development Authority which has a significant role in identifying sites for new landfills. Ministry of Environment and Forests (MoEF) of the federal government, Central Pollution Control Board (CPCB) and Delhi Pollution Control Committee (DPCC) can intervene in environment and health related matters. MCD is further assisted in the discharge of its responsibilities by an informal network of about 50,000 waste pickers, scrap dealers and waste depot owners who ensure that recyclables from the waste are retrieved, segregated and sold to the recycling industries.

\section{Municipal solid waste and changing perspectives}

\subsection{Municipal solid waste}

Municipal solid waste (MSW), or 'trash' or 'garbage' can be described as waste generated by households, commercial and institutional establishments such as markets, schools and offices and municipal services such as the sweeping of streets and the maintenance of parks. The chemical composition of MSW in high and low/middle income countries shows considerable variation. The percentage of non-biodegradable recyclables, paper, plastic, cardboard, cloth, metal and glass is considerably higher as compared to the biodegradable, food and other organic waste in the rich countries. These countries have the infrastructure to ensure collection of source segregated waste. In poorer countries the emphasis in on maximizing centralized collection. Waste pickers take away recyclables from the waste dumps further eroding its calorific value and raising its moisture content. Again, due to the difference in the system of collection, there are no inerts; stones, silt and other inorganics in the MSW of an advanced country since it is collected separately. In a low income country it can be a substantial component. According to a recent study, a major fraction of urban MSW in India is organic matter (51\%). Recyclables are $17.5 \%$ of the MSW and the rest $31 \%$ is inert waste. The average calorific value of urban MSW is $7.3 \mathrm{MJ} / \mathrm{kg}$ $(1,751 \mathrm{Kcal} / \mathrm{kg})$ and the average moisture content is $47 \%$ [3, p. 33].

\subsubsection{From solid waste management to sustainable solid waste management}

The traditional rationale of solid waste management has been the protection of environment quality and human health and the strategy to achieve it emphasized the principles of reduction, reuse and recycling. The disposal of the residue after exhausting the last two means of processing waste was regarded as a non-issue because it was assumed that it final receptacle either land, air or water had selfrenewing capacity to ensure its total elimination. This comfortable productionconsumption-waste link up became a subject of debate by the end of the century. Worldwide adoption of fossil fuel based production was satisfying consumption needs but the waste that was being generated in the process could no longer be assimilated. Loss of biodiversity, discovery of high levels of mercury in a 
common dietary items, the humble fish, and scientific evidence that global warming which was likely to melt glaciers and cause floods and droughts was due to the enduring presence in the atmosphere of carbon dioxide generated by the burning of fossil fuels helped shape consensus about a new paradigm for economic development and also for waste management. In 1992, at the UN Conference on Environment and Development, at Rio de Janeiro it was agreed that every country had the right to develop but is should be as the Bruntland Commission which provided the intellectual resource for the Conference put it, according to a "sustainable" model, "an eco-friendly type of growth that is less material and energy intensive and more equitable in its impact" [4]. This suggested that the traditional goals of municipal solid waste management needed to be redefined. P. Schubler, K. Wehrle and J. Kristen who in 1996 formulated a framework for low income countries, said the revised goals could be, protection of environmental health, promotion of quality of urban environment, support to the efficiency and productivity of the economy and generation of employment and income. "The essential condition for sustainability," they add, "implies that the waste management systems must be absorbed and carried by the society and its local communities. These systems must in other words be appropriate to the particular circumstances and problems of the city and the locality, employing and developing the capacities of all stakeholders, including the households and communities requiring service, private sector enterprises and workers(both formal and informal)and government agencies at the local, regional and national levels” [5].

\section{Sustainable waste management hierarchy}

The widely used waste management hierarchy developed by the Earth Engineering Center at Columbia University [3, p. 40] indicated above reflects the priorities that were agreed upon at Rio.

\subsection{Unsanitary landfills and open dumps}

Unsanitary landfill which is the cheapest and most utilized waste disposal option by low income countries - 90\%, in the case of India - is placed last in this hierarchy because of its huge negative impacts upon human health, environment quality and urban opportunity. Waste dumps are the breeding ground for rodents and insect vectors which spread diseases like cholera, dengue and plague. Fires, which can go on for days, and which are started at dumps and landfills to retrieve recyclables, release toxic gases that cause respiratory disease and furans and dioxins which are known carcinogenic substances. It was estimated in a study in 2010 that in Mumbai where 2\% of the total MSW generated is openly burnt on the streets and $10 \%$ burnt in landfills, 10,000 gms of furans and dioxins substances are released into the air. How hazardous this is, can be gauged by the fact that the Delhi Pollution Control Committee require WTE at Okhla to maintain a level of $0.1 \mathrm{mg} / \mathrm{cm}$. In Mumbai, open burning of MSW was the largest emitter of carbon monoxide (CO), particulate matter (PM), carcinogenic 


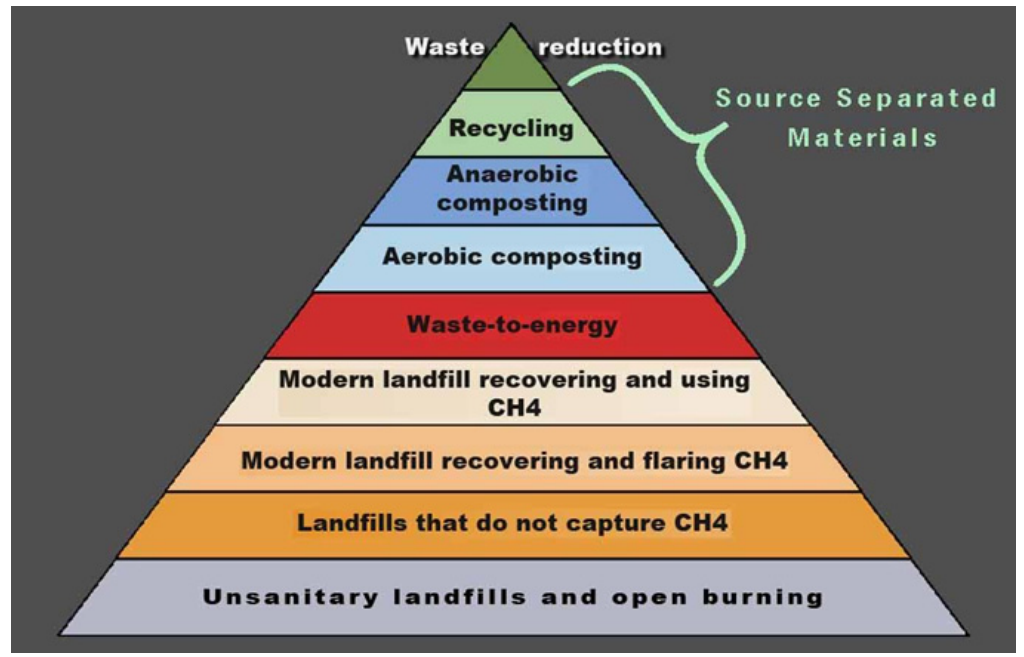

Figure 1: $\quad$ Solid waste management hierarchy.

hydrocarbons (HC) and nitrous oxides (NOx), among activities that do not add to the economy of the city. Unsanitary landfills can contaminate ground and surface water resources when the leachate produced percolates through the soil strata into the groundwater underneath or is washed as runoff during rains. Leachate generally contains organic chemicals formed by anaerobic digestion of organic waste and heavy metals leached from inorganic waste. The heavy metal generally observed in leachate are Lead $(\mathrm{Pb})$, Cadmium (Cd), Chromium (Cr) and Nickel (Ni). All these heavy metals are characterized as toxic for drinking water. Nitrates present in the environment can also be reduced to nitrites due to leachate. Nitrites consumed through drinking water can oxidize haemoglobin $(\mathrm{Hb})$ in the blood to methaemoglobin (met $\mathrm{Hb}$ ), thereby inhibiting the transportation of oxygen around the body. The practice of unsanitary landfilling not only occupies precious land resources near urban areas; it also degrades the quality of land and soil in the site. Presence of plastics and heavy metals in the soils make it unfit for agriculture and emissions of methane and structural instability of the land make it unfit for construction activities. Massive remediation efforts which are time and infrastructure intensive, alone, can make the land useful [3, pp. 62-63]. With land becoming increasingly scarce, landfills can only grow upwards. In 2000 at the Payatas dumpsite near Manila, due to strong winds, a section of the 50 feet garbage mountain slid down killing 137 people. A similar disaster can occur at any time in most cities in low income countries.

\subsection{Sanitary landfills}

From the environmental perspective the most damaging aspect of unsanitary landfills is emissions of methane generated due to its anaerobic conditions. Methane is 21 times more potent than carbon dioxide as a greenhouse gas and 
71 times as much in the first year. The United Nations Environment Programme supports an alternative in the form of a sanitary or engineered landfill where physical, chemical and biological processes are in place to compact the waste, capture and purify leachates and ideally control and utilize methane emissions for fuel purposes. Until 2011, eight such facilities have been constructed in India. These are also not working satisfactorily due to lack of funds for maintenance. This difficulty can be mitigated if these facilities are required to serve a larger number of urban local bodies and their use reduced by seeing them as an integral part of a hierarchy where there are higher waste disposal options [3, pp. 45, 51, 67-68, 73-76].

\subsection{Recycling and composting}

From the sustainability perspective, recycling is the highest waste management option for a low income country. Thousands of waste workers retrieve recyclables from the designated and improvised dump sites and streets for sale to the recycling industry. According to one estimate, the material recovery rate is $20.7 \%$ from the formal system as compared to $30 \%$ in advanced countries which have elaborate infrastructure for collection of source segregated waste and mechanical devices for its sorting. Recycling meets livelihood requirements, saves need for virgin materials and avoids energy costs required for extraction. It also reduces the work load, and burden of collection and transport of a perpetually underfunded and understaffed municipality, thereby freeing it to perform other civic responsibilities. However, the limitations of waste picking to improve the system and finances of the waste pickers need to be recognized. It is driven by market considerations and restricted by individual health and age factors the overwhelming bulk of the waste that is screened is left at the spot where it was discovered. Since waste pickers are prone to injury and infection, they are an imposition on the State which is constitutionally obligated to protect their health. They can be a source of resistance to a city's efforts to maintain clean public spaces and promote scientific disposal. Given the high fraction of biodegradables in its waste, composting can be a source of both environmental and social benefits. It can return to the soil macro nutrients like Nitrogen, Phosphorous and Potassium besides essential micro nutrients. It can provide employment to low skilled persons in decentralized composting projects based on vermiculture in public parks and those maintained by private companies and resident associations. However this can happen only if segregated green waste is available. In low income countries since only mixed waste is collected, large scale projects based on anaerobic digestion which yields both organic manure and a fuel source in the form of a mix of methane and carbon dioxide are irrelevant. Nevertheless, centralized aerobic composting projects using the windrow method to which 1,000 tons of waste a day can be directed has appeal to municipalities. This is because it reduces the load which requires final disposal and there is a market for this manure which is reputed for sharply increasing plant growth. Private companies have grasped this and there has been an increase in recent years in the number of public-private partnerships for setting up such plants. From the sustainability perspective this is an 
unsatisfactory situation since due to the presence of inorganics such as plastics in the input, heavy metals like Zinc, Copper, Cadmium, Lead, Nickel and Chromium leach in the manure. Human health can be endangered if this manure is used for agriculture. Further, up to $60 \%$ of the input is a reject and requires to be landfilled. Since it is calorie rich, it amounts to burying an energy source [3, pp. 78-80, 84].

\subsection{Waste to energy (WTE)}

Waste to energy can be defined as a process of controlled combustion, using an enclosed device to thermally breakdown combustible solid waste to an ash residue which is $10 \%$ of the original volume of waste [3, pp. 45, 102, 107]. Due to advance in pollution control technology since the 1990s, in modern WTE facilities impurities in a mixed input can be fully captured. The bottom ash from WTE combustion contains only inert inorganic materials and minerals while the fly ash alone has pollutants and requires disposal in a sanitary landfill. With application of more advanced technologies as is the case in some WTE projects in Japan and Europe the entire ash can be made innocuous. WTE is an expensive technology developed by the western world. The capital cost of building a WTE plant is US\$51,000 per ton of waste processed. In comparison windrow composting costs only $\$ 4,500$ per ton. The rationale for the high position of WTE in the sustainable waste management hierarchy lies in the fact that only this technology can virtually eliminate the difficult to recycle waste and noncompostable rejects whose quantum is increasing with the expansion of consumption and sophistication of production processes in all countries. If a WTE is in place, scarce urban area land will be needed only for a sanitary landfill. Besides, there is no conflict with recycling or composting. In the city of Pune in India which has a long history of providing protection and facilities to waste workers in the informal sector and where 7,000 waste workers are efficiently engaged and where as much as $56 \%$ of recyclables are recovered, the total waste reduction is only $4 \%$. The rest, about 330,000 tons per year of MSW has to be landfilled or composted and compost rejects are ideal feed for WTE boilers because they are calorie rich. WTE promotes the recycling industries by contributing ash and metals which were originally in the inputs and remain unaffected by incineration. Ash can be used to make bricks and other construction material. No methane gets generated in WTE incineration and electricity produced by utilizing the heat qualifies for international funds through the clean development mechanism (CDM) of the UN Framework Convention on Climate Change (UNFCCC) since it is based on a "renewable" source and an equivalent amount of the finite supply of coal and natural gas is saved in the process. The high cost of WTE can be offset by having WTE cater to a region with many cities since the facilities are designed to process at least 1,000 tons of waste a day [3, pp. 45, 102, 107]. 


\section{Towards sustainable MSW management in Delhi}

\subsection{MSW rules 2000}

A legal framework for sustainable management of MSW in Delhi came into force on 25.9.2000 when Government of India's MoEF notified the Municipal Solid Waste (Management and Handling) Rules 2000. These rules required State /District level authorities and the municipalities to ensure the collection, segregation, storage, transportation and disposal of waste from the entire area in their jurisdiction with the exception of waste covered by the rules for biomedical and hazardous waste. Horticulture and construction and demolition waste was to be separately collected and awareness programs were required to be held to promote segregation, recycling and reuse. Implicitly suggesting that careless disposal of biodegradable waste was a major reason for urban squalor, soil degradation and loss of natural materials, the rules mandated that biodegradable waste be disposed of by composting, vermicomposting, anaerobic digestion and mixed waste by recycling, incineration, with or without energy recovery and pelletisation in that sequence. CPCB was authorized to lay down the norms for the advanced technologies. Unsanitary landfills were to be phased out and parameters for sanitary landfills were indicated [6].

\subsubsection{Rules implementation in the early years}

In the initial years, Delhi government and the MCD adopted a soft and innovative approach for advancing towards a more sustainable waste management regime. The focus was on building awareness about waste segregation among stake holders and facilitating their cooperation through placement of blue and green bins, one for "dry" non-biodegradable waste and the other for "wet" organic waste in strategic places and on projects for promoting community level recycling and composting. Delhi government began to give small annual grants to schools and colleges to maintain eco clubs and subsidized compost project undertaken by resident welfare associations (RWAs) with assistance of non-governmental organisations (NGOs) [7]. As an experiment to improve collection levels and highlight its new perspective, MCD engaged private companies for 6 of the 12 zones to collect and store segregated waste in structures the companies promised to redesign for this purpose. Subsequently, waste was to be transported in colour coded vehicles to the disposal sites [8]. Further, MCD while taking steps to compact waste in the 3 existing landfills started negotiations for 3 additional spaces where landfills according to new specifications could be built.

5.1.1.1 Factors that led to WTE By the middle of the first decade, it became clear that there was little change in the existing unsatisfactory situation. In 2006, CPCB which had been since 1998 on Delhi High Court's orders, conducting inspections and submitting reports every four months on the status of MSW management in Delhi pronounced that "practically no segregation of waste was practised in Delhi." CPCB noted that the 3 existing landfills "were stretched 
beyond their capacity" and chastised the MCD for the slow progress in finalising new sites. About Delhi's record at composting, it said only 300 tons was composted at the 3 mechanical biological plants and 500 tons capacity lay unutilized. It attributed this to vanishing village spaces and suspicions about its "fertile quality". Further, it noted, up to $60 \%$ of waste input was being discarded and adding to the burden of the landfills. Going forward, CPCB's view was that "setting up integrated waste processing facilities (composting/ waste to energy /RDF for processing of waste was required [9]. Delhi's waste is expected to grow at $8 \%$ and become between 17,000 and 25,000 tons a day by 2021, according to a study sponsored by Government of India and Government of NCT [10]. What was needed was a new method which could reinforce the existing methods and safely collapse huge quantities of mixed urban waste. The fact that India was going to host the prestigious Commonwealth games in 2010 meant that there was not much time to decide what this would be. The Ministry of New and Renewable Energy of the Government of India, was providing subsidies between INR 50,000 and INR 1 lakh per MW if a renewable energy source could be used and garbage was officially such a source. Against this background, when 3 Indian companies expressed their willingness to enter separately into a partnership with governmental authorities to set up and manage WTE plants with modern technology, Delhi's state government and municipalities gave them full support. In January 2008, Jindal Urban Infrastructure Ltd. (JUIL), now Jindal Ecopolis, was awarded a contract to set up a plant on government land at Okhla to generate $16 \mathrm{MW}$ of electricity by using up 1,300 tons of mixed waste. The objections of citizen and environment groups who maintained that the siting norms indicated in the MSW rules 2000 had been ignored and that an Environmental Impact Assessment (EIA) as per the standards of the 2006 notification of the MoEF on the subject had not been carried out were set aside [11]. Government authorities were similarly dismissive of the criticism of the EIA report about the project at Ghazipur landfill which supposedly did not mention the dates of the public hearing and numerical strength of the gathering which was in its favour [12]. The landfill received about 2,000 tons of garbage every day. The contract with East West Processing Company Limited (EWPCL), required it in due course to divert 1,300 tons to a facility where it was to be processed to reduce moisture content and made into pellets in the first phase. Later this refuse derived fuel (RDF) was to be combined with mixed waste to generate $12 \mathrm{MW}$ of electricity. At the newly constructed sanitary landfill (SLF) at Narela_Bawana which is also Delhi's first SLF, the Ramky group, is expected by the end of 2013 to be able to use up to 1,300 tons of garbage a day in the first phase and 4,000 tons in the next phase to make RDF pellets. There is a provision here for a compost plant as well. $12 \mathrm{MW}$ of electricity is expected to be generated when the plant becomes fully functional.

\section{Recent debates relating to WTE in Delhi}

The prospect of waste stabilization at the landfills at Okhla and Ghazipur has led to experiments at landfill gas tapping by Tata Environment Research Institute 
(TERI) and the Jamia Milia University in the first case and Gas Authority of India Limited (GAIL) in the second. The hope is that spots can be discovered from where methane can be captured for regular supply as a fuel source displacing an equal requirement of coal or natural gas. However, in Delhi, since January 2012, when the Okhla plant became functional any 'feel good' sentiment about WTE on account of the environmental and social factors has been overshadowed by strongly articulated fears of polluting emissions, especially of dioxins and furans and of loss of livelihoods. A citizen's collective has maintained its case against Jindal Ecopolis in the Delhi High Court since 2009 despite periodic tests being carried out by CPCB which show that the emissions are within the levels that were set by its subordinate body, DPCC. In March 2013 a committee appointed by the National Environment Tribunal had a sample tested from the stacks which showed the levels to be 30 to 40 times higher than the prescribed levels. Even as it was being loudly suggested that the plant be closed, CPCB expressed its full confidence in the plant's advanced pollution control systems and the capacity of its engineers to adapt a western technology meant for mixed waste to the specifics of Delhi waste [13]. What is not generally known is that furan and dioxin levels cannot be read on line and there is a 30 day lag between submission of a sample for analysis and the laboratory and different laboratories can give varying reports about the same sample. It also means that improvements made to maintain prescribed standards need to be given time to prove their worth [14]. Regarding loss of livelihoods, a socio-economic survey was carried out in August 2012 in three villages in the neighbourhood of the Okhla landfill which is about $8 \mathrm{Km}$ from the Okhla WTE facility. $88 \%$ of the people in these villages depended on the landfill as their main source of income. A $21 \%$ decrease in income across all waste occupational categories was recorded. A decrease in income was also seen in responses relating to questions about getting loans, eating meat/fish and celebrating major festivals [15]. From the sustainable MSW management perspective, waste pickers incomes can improve if Delhi's municipal organisations provide them legal status and require households and institutions to give them their waste. It can create waste transfer stations or material recovery facilities (MRFs) for them where they can safely sift and segregate waste. Delhi government can give more incentives to industries which recycle and "up-cycle" (utilize discards as raw materials without changing their chemical composition) waste and make new products. It can require offices in Delhi to buy products with recycled content.

\section{Conclusion}

With the three unsanitary landfills still very much in use for depositing the bulk of 8,000 tons of MSW that Delhi daily generates, it is clear that any contribution that WTE projects can make towards a more environmentally benign socially responsible and cost effective waste management regime in the city can only be over the long term. So the real issue is, whether and on what terms will the WTE facilities endure. The first WTE project for MSW set up in Delhi in 1985 with Danish technology at a cost of US\$9.1million was closed down due to 
unsatisfactory results of trial runs. This was attributed to a mismatch between the input stream and an alien technology, a matter which, by and large, has been resolved in the case of the present projects. These facilities are not only costly to construct but also very expensive to maintain. The owners of the Okhla plant have been incurring a loss of over $\$ 333,000$, or 200 million INR (60 INR = US\$1) a month since under the terms and conditions of the contract they cannot charge MCD a tipping fee and have to sell electricity to the managers of Delhi's grids at the paltry price of 5 cents per unit [16]. Public money will have to be pumped in to keep the plant going but it should be an affordable sum. Less public money will be needed if the WTE plants operate efficiently. For this, there has to be source segregation and separate collection of construction and demolition waste. This way chlorine containing plastics and metals whose combustion generates furans and dioxins can be avoided as also inerts which block the buildup of high temperatures. To optimize its social environmental and economic benefits WTE has to be restricted to non-compostable and nonrecyclable waste through better integration with the recycling, composting and small scale anaerobic digestion or bio methanation options. Low income levels of waste pickers can improve if Delhi government and the municipal authorities can work with select environment NGOs and waste picker cooperatives to ensure more exhaustive source segregation and generation of organic manure through vermicomposting in public parks and private gardens. The biomethanation unit in Delhi government Secretariat which uses food and horticulture waste to generate a fuel supply for its cafeteria and compost slurry for its gardens deserves multiplication.

\section{General observations}

Given the shortage of land, no other waste management option can match WTE in resolving a city's problem of safe and scientific disposal of growing piles of mixed waste with its attendant hazards. That is why there are more than 600 such projects in locations in all parts of the world. This study suggests that the durability of a project which can be a source of widespread environmental, social and economic benefits will depend on a number of factors. The first is a firm political consensus which is not shaken by NIMBY inspired protests of RWAs and misinformation campaigns of anti-incineration NGOs. Continuous electoral terms for the same political party at the Centre and state level has a major role in ensuring this. The second factor is the ability of state authorities to subsidize the maintenance of the facility which will have to be under taken in due course despite the operating companies having deep pockets.. The state's ability to do so is linked with the health of the country's economy. The last factor is governmental capability for organising various stake holders so that source segregation, composting and recycling is maximized. Showcasing of success stories can make a difference. 


\section{References}

[1] www.delhi.gov.in/DoIT/DES/Publication/Abstract/SA2012.pdf

[2] http://www.business-standard.com/article/economy-policy/delhi-largestmunicipal-solid-waste-producer-in-country-survey-109082400086_1.html

[3] Annepu, R.K., Sustainable Solid Waste Management in India. Online, 2012. www.seas.columbia.edu/.../Sustainable\% 20Solid\%20 Waste\%20 Management\%20in\%20India_Final.pdf

[4] Report of the World Commission on Environment and Development; Our Common Future. http://www.un-documents.net/wced-ocf.htm

[5] Ali, M., Cotton, A., Westlake, K., Down to Earth-solid waste disposal in low income countries, Loughborough University UK, p.71, 1999.

[6] The Municipal Solid Waste Management and Handling Rules, 2000. www.dpcc.delhigovt.nic.in/act_municipal.htm

[7] Delhi Government, Four years, p.47, 2002.

[8] Chapter 12: Solid Waste Management, p.3, 2006 www.ccsindia.org /ccsindia/pdf/Ch12_Solid\%20Waste\%20

[9] Management of Municipal solid waste in Delhi and suggested action plan. 2006.http://www.cpcb.nic.in/Highlights/2006/MUNICIPALSOLIDWAST EMANAGEMENT\%5B1\%5D.pdf

[10] Solid Waste Management in Delhi-Chapter10. [2011] delhiplanning.nic.in /Reports/Delhi 21/Chapter 10.

[11] Shah, D., The Timarpur-Okhla Waste-to-Energy Venture. www.noburn.org/downloads/Timarpur.pdf

[12] Moyna, Patronising dirty technologies, 2012, www.downtoearth.org.in

[13] Messenger, B., Report finds significant emission breaches at waste to energy plant in Delhi http://www.waste-management-world.com /articles/2013/06/report-finds-significant-emissions-breaches-at-waste-toenergy-p.html Also, Chawla, B. L., Personal Communication, $6^{\text {th }}$ August 2013, Senior Environment Engineer, Delhi Pollution Control Committee.

[14] Name withheld, Personal Communication, $8^{\text {th }}$ August 2013, Senior Engineer at Jindal Ecopolis.

[15] Chintan Publications, Give back our Waste, pp. 10-11, 2012, www.chintan-india.org/publications_research_reports.htm

[16] Name withheld, Personal Communication, 8th August 2013, Senior Engineer at Jindal Ecopolis. 